\title{
XLIII. Some applications of physics and mathematics to geology
}

\section{Chree M.A.}

To cite this article: C. Chree M.A. (1891) XLIII. Some applications of physics and mathematics to geology, Philosophical Magazine Series 5, 32:197, 342-353, DOI: 10.1080/14786449108620194

To link to this article: http://dx.doi.org/10.1080/14786449108620194

曲 Published online: 08 May 2009.

Submit your article to this journal ๘

Џ Article views: 2

Q View related articles ¿ 
almost infinite variety of colour of allotropic silver, whilst normal salts of silver when formed with colourless acids are mostly colourless. On the other hand, the greater activity of allotropic silver and its less specific gravity would seem to indicate a simpler molecular constitution than that of normal silver.

XLIII. Some Applications of Physics and Mathematics to Geology. By C. Chree, M.A., Fellow of King's College, Cambridge.

[Continued from p. 252.]

\section{Part II. Some Geological Theories.}

TTHE belief that the present spheroidal form of the earth necessarily betokens a previous liquid, or at least plastic, condition seems amongst Geologists almost as universal as the belief that the earth but for the development of rotation must have been a spherical body. Whether this latter conclusion has any satisfactory basis apart from philosophical speculations, it is not my present object to inquire. But supposing, for the sake of argument, that the natural form of the earth as undisturbed by rotation is spherical, the conclusion that it ever was in a liquid or even in a plastic state throughout is, according to the preceding results, not established by its present spheroidal form. Yet even in such a standard work as Geikie's 'Text-book of Geology,' after reading the discussion on p. 12 and the footnote attached, I fail to detect a trace of the idea that the polar flattening might be called forth by rotation in a truly solid body.

Various geological writers, it is true, speak of a solid earth as capable of changing its form, but they seem in reality to regard the change as due to rupture or to the development of a plastic condition. This appears, for instance, to be the view actually held by Mr. Herbert Spencer in a short paper* entitled "The Form of the Earth no proof of Original Fluidity." This paper has been referred to with a somewhat inaccurate conception of its value and results by two recent geological writers, so it claims some notice at our hands. The first of the two writers referred to, Mr. W. B. Taylor †, says :- "It is now nearly forty years since Herbert Spencer, with a juster physical insight [than Sir W. Thomson and Professor Tait], contended and satisfactorily showed that a solid earth (of any shape) would assume the oblate spheroidal

* Phil. Mag. [3] vol. xxx. 1847, pp. 194-196.

$\dagger$ American Journal of Science, vol. xxx. 1885, pp. 258, 259. 
form due to its rate of rotation, as certainly and promptly as if it were liquid." The other writer, Mr. A. Blytt*, amongst other references to the paper says, "I believe that Spencer is the first who expressed the opinion that even a solid earth can change its form."

Mr. Spencer, after some statements as to the relative strength and agility of large and small animals, such as elephints and fleas, formulates the general result that the strength-called also "resistance to fracture"-of a solid structure varies as the square of its linear dimensions, while the "agencies antagonistic to cohesive attraction," i.e. gravitational and "centrifugal" forces, \&c., vary as the cube. Excepting a statement that this is obviously true of simple longitudinal and torsional stress, the following is the sole proof of his very general law supplied by Mr. Spencer :"The strength of a bar of iron, timber, or other material subjected to the transverse strain varies as $\mathrm{BD}^{2} / \mathrm{L} ; \mathrm{B}$ being the breadth, D the depth, and L the length. Suppose the size of this bar to be changed, whilst the ratios of its dimensions continue the same ; then ... the strength will vary as $\mathrm{D}^{2} \ldots$.." (p. 195). The following is the conclusion drawn by Mr. Spencer:- "Viewed by the light of this principle, the fact that the earth is an oblate spheroid does not seem to afford any support to the hypothesis of original fluidity as commonly understood. We must consider that, in respect of its obedience to the geo-dynamic laws, the earth is fluid now and must always remain so; for the most tenacious substance with which we are acquainted, when subjected to the same forces that are acting upon the earth's crust, would exceed the limit of self-support determined by the above law, before it attained $\frac{1}{1,000,000,000}$ th of the earth's bulk" (p. 196).

Perhaps if one knew what Mr. Spencer means by "the limit of self-support," and what is the exact distinction he draws between "Huidity as commonly understood" and "Huidity in respect of obedience to geo-dynamic laws," one might be in a position to form some estimate of his degree of physical insight; but so fir as I can see all he satisfictorily shows is an extraordinary agility in jumping to conclusions. If his meaning is that deformation must accompany the action of gravitational and centrifugal forces, he might, if Maxwell's view be correct, have added to the denominator of his estimate as many $U^{\prime}$ 's as the printer could spare; but if it is the rupture of an elastic solid or its transformation into a

* Phil. Mag. May 1889, p. 415. Translated from Nyt Magazin for Naturvidenskaberne, Bd. xxxi. 1889. 
plastic state to which he refers, as seems almost certain from the context, he must have formed an extremely low estimate of what strains a solid can stand.

In the same passage Mr. Blytt refers to Mr. Peirce*, Sir J. W. Dawson $\dagger$, and Professor J. E. Todd $\ddagger$ as holding that a solid earth will alter its shape if the rate of rotation vary. The views of Mr. Peirce I have not seen, but the other two writers mentioned regard the solid earth itself as changing shape only by means of a succession of what we may term catastrophes. Their view's seem identical with those which Mr. Blytt's translator ascribes to him in the following words : - "The sea adjusts itself in accordance with the smallest change in the length of the day .... But the solid earth offers resistance to change of form, and begins to give way only when the tension reaches a certain amount" (p. 418). $\mathrm{Mr}$. Blytt makes several distinct references to the subject, and his remarks are not perhaps always strictly consistent. This, however, is hardly to be wondered at since he gives as the result of his investigations :- "As has been stated, there prevails ... a disagreement as to how far the earth will change its form, in case the centrifugal force varies. Thom:on is most inclined to believe that it will not; Darwin is of opinion that it will. And among other physicists whom I have consulted a similar divergence prevails upon this point. One thinks that a lengthening of the day even by several hours will be incapable of altering the form of the solid earth; another believes that the solid earth will probably change its form just as easily as the sea" (p. 421).

If Mr. Blytt should ever have further occasion to consult physicists on this or any allied point, he would find an exact definition of such terms as solid a certain amount of protection from à priori speculations. Mr. Blytt's own principal view seems due in part to an erroneous interpretation of Tresca's experiments on the flow of metals under pressure. They do not in reality justify his statement "By reason of the enormous pressure which prevails in the interior of the earth, it must be supposed that masses from a certain depth are more or less in a plastic state" (p.417). It was in fact pointed out some years ago by the Rev. Osmond Fisher $\$$ that the existence of an orifice from which the metal can flow constitutes a complete difference between the conditions of

* Proc. Amer. Acad. Arts and Science, vol. viii. 1873, p. 106.

+ 'Story of the Earth and Man,' ninth edition, pp. 291, 292.

$\ddagger$ American Naturalist, vol. xvii. 1883, pp. 15-26, specially pp. 18, 19. $\S$ 'Physics of the Earth's Crust,'] ]st edition, 1881, footnote p. 120. 
Tresca's experiments and the state of a body subjected to nearly uniform pressure all round.

Mr. Blytt apparently does not stand alone in believing Sir W. Thomson to hold that the solid earth is incapable of altering its form as the rotation alters, and that it possesses the same eccentricity as when it soliditied. Professor Darwin in 'Nature,' vol. xxxiv. (1886), pp. 420-3, seems also to put this interpretation upon a passage he quotes from $\$ 830$ of Thomson and Tait's 'Natural Philosophy.' Supposing this interpretation correct, Professor Darwin's opinion that Sir W. 'Thomson does not allow "a sufficient margin for uncertainties" expresses only a part of the objections I shonld entertain. I find it difficult, however, to believe that Sir W. Thomson, who elsewhere gives data for the eccentricity produced by rotation in solid spheres of steel, can actually suppose no change at all in the eccentricity to follow an alteration in the angular velocity. Still it must be confessed that though the passage contains the statement, "It must necessarily remain uncertain whether the earth would from time to time adjust itself completely to a figure of equilibrium adapted to the rotation," its most natural interpretation is that given by Professor Darwin. I need hardly say that the conclusion that the earth, however solid, would retain a constant eccentricity while the rate of rotation varied, seems to me directly opposed to the conclusions to which the elastic solid theory leads.

Professor Darwin himself, in his paper in 'Nature,' refers to Tresca's experiments and thinks it probable there would be from time to time a flow of material as the angular velocity altered. One of the "uncertainties" he refers to is the possibility that, in accordance with Dr. Croll's* views, a greater rapidity of denudation in equatorial than in polar regions may have reduced the eccentricity markedly below the value it possessed when the earth solidified. He does not seem, however, to refer to the considerable change of eccentricity that might occur in a solid through mere variation of elastic strain.

As regards the present state of the earth's interior there are, according to Geikie's 'Text-book,'p. 49, only three theories which merit serious consideration, viz.:-

(1) That there is a solid crust and a molten interior.

(2) That with the exception of local vesicular spaces the earth is perfectly solid.

(3) That the earth consists of a solid crust and nucleus with an intervening liquid layer.

* 'Climate and Time' (1885), p. 336. 
According to the 'Text-book,' the theory of a thin crust containing liquid or viscous matter is exposed to "weighty and indeed insuperable objections," p. 18 , and "is now abandoned by most geologists," p. 43.

According to Dr. Croll" the "general opinion among geologists" is that the earth "consists of a fluid interior surrounded by a thick and rigid [really solid] crust."

Prolessor Prestwich $\dagger$ believes that "the crust rests on a yielding substratum, and that of no great thickness." In fact he advocates the third of the above-mentioned theories, and believes 30 miles to be probably in excess of the crust's thickness. Most writers on the subject appear to have subsidiary theories of their own.

Whether the assurance that the question is beyond the reach of experiment accounts for the multitude of theories and the confidence with which they are proposed, is a question for philosophers not mathematicians to consider, but it seems $\grave{a}$ priori a possible explanation of such a declaration of faith as that of Mr. W. B. Taylor $\ddagger$ :- "The liquidity of our globe, and the relative thinness of its encrusted envelope, - as attested by all legitimate geological induction,-will be assumed withorit misgiving or hesitancy ; and the supposed mathematical arguments for its solidity ignored as essentially fallacious and wholly inconclusive."

Of course, if the geological evidence were conclusive, it would be mere waste of time further to consider the matter, but the evidence that satisfies Mr. Taylor does not seem to carry conviction to all geologists even in America. Mr. G. F. Becker §, for instance, who appears to have some practical experience, says :- " For a considerable number of years I have constantly had the theory of the earth's solidity in mind while making field observations on upheaval and subsidence, with the result that to my thinking, the phenomena are capable of much more satisfactory explanation on a solid globe than on an encrusted fluid one."

It may thus be not wholly unprofitable to glance briefly at some of the arguments which some of the advocates of the several theories base on their ideas of the properties of solid bodies.

Mr. Taylor's object is to get an equatorial circumference some 10 per cent. in excess of its present value, so as to account for the lateral compression at the surface observed in

* 'Climate and Time,' p. 395.

† 'Geology,' vol. ii. p. 540 .

$\ddagger$ American Journal of Science, vol. xxx. (1885), p. 250.

$\$$ American Journal of Science, vol. xxxix. (1840), pp. 351, 352. 
mountain-chains. Thus, following Professor Darwin*, he supposes the earth to have once possessed a much greater angular velocity than at present, and speaks of a " consistent crust (of some few miles thickness)" as having formed "when the rotation of our planet was at four times its present rate" (l.c. p. 257). The equatorial radius would then have been, he says, some 4359 miles, and the polar some 3291 . The change of shape, as the rotation fell off, would account, he thinks, for observed phenomena. He considers his conclusions opposed by Sir W. 'Thomson's theory that the earth solidified throughout and retains at least approximately its original eccentricity. It is on this point that he refers to the datil supplied by Mr. Herbert Spencer's "juster physical insight;" and he adds, apparently as his own contribution to the argument,- "The supposition that a granite mountain or equatorial protuberance 400 miles high or 100 miles high could for a moment support itself, would hardly be entertained by a practical engineer ;" and in a footnote, "The limiting modulus of height of a granite pyramid (equalling one side of its square base) is somewhat less than eleven miles" (l. c. p. 258). I am quite ready to agree with Mr. Taylor that if solidification occurred under the conditions he supposes the eccentricity must have altered enormously and that in a non-elitstic way, and I hardly suppose that Sir W. Thomson would oppose this view. No one, however, so far as I know, has propounded the theory of an elastic solid spheroidal earth of eccentricity 65 rotating completely in six hours, so that the investigation of the strains and stresses required by such a theory is unnecessary. I can quite imagine that on any probable theory of density the magnitude of the strains is hardly likely to be consistent with the application of the mathematical theory of elasticity. The force of Mr. Taylor's remarks as to the pyramid I, however, fail to see. Such an isolated mass exists under totally different conditions from any portion of a solid sphere or spheroid, and one might as well argne as to the impossibility of a liquid interior from the fact that an isolated liquid column 100 miles high has not yet been observed on the earth's surface. If Mr. Taylor were, however, to calculate the strains and stresses in such a thin shell as he supposes, of material showing anything resembling the structure of ordinary rock, with a rate of rotation such as he mentions, I very much doubt whether he would find it in an essentially better position than his imaginary py ramid.

Atter this criticism Mr. Taylor considers the question of the probable degree of rigidity of our planet quite irrelevant, but

* Phil. Trans. (1879), p. 532. 
the "temptation is strong to waste upon it a collateral glance" (l.c. p. 259). Accordingly he crushes Sir W. Thomson's argument * from the tides by the remark-" That a siliceous crust of 20 miles average thickness, and an overlying aqueous ocean of three miles average depth, should have (as required by the argument) so equal a coefficient of mobility, that sea and land could thus together ' rise and fall,' might well be pronounced incredible" (l. c. p. 260).

$\mathrm{He}$ regards $\mathrm{Sir}$ W. Thomson as very seriously damaging his own argument by the admission that tides comparable in magnitude with those observed would occur even in a solid earth of steel. It does not seem to have occurred to him that the existence of a difference between the motions of the land and water may constitute an argument for solidity $\dagger$.

Mr. Taylor admits one difficulty in his theory, viz. the nature and local characteristics of the plications actually observed ; and remarks:- "While the force at the command of the rotating planet is abundantly sufficient ... evidently some supplementary considerations are requisite to give the observed direction to this force," ... " "The mere mechanical difficulty, however, of transmitting stresses through comparatively undisturbed areas of bundreds of miles of a flexible, friable, and practically plastic crust-with a large coefficient of viscous friction beneath-is not so formidable as might at first appear. It must be borne in mind that the pressures derived from an action so slow as from century to century to be scarcely sensible, are of an order of very great intensity, but of very small quantity" (l.c. p. 265). Mr. Taylor also infers from "various considerations" that " in all ages mountain building has been at a maximum ; that is, the uplifted heights have been the greatest which the average thickness of the crust at the time was capable of supporting; so that the former has been a constant function of the latter, the ratio being probably not far from one-fifth" (l.c. p. 265). Mr. Taylor does nut state that this law of the uplifted heights is true of all lands as well as of all time, but the possibility that such may be the case is rather alarming. He enters in fact into no unnecessary details as to how he reached his conclusions, so that all one can say is that measured by his own standard he is certainly not inferior in physical insight even to $\mathrm{Mr}$. Herbert Spencer. Perhaps when he comes to deal with the "supplementary considerations" he may supply sufficient data for the mathematician to follow him.

Professor Prestwich, in his 'Geology,' vol. ii., regards the

* Natural Philnsophy, vol. i. part ii. $\$ 833$.

$\dagger$ See his remarks, l. c. p. 260 and footnote. 
"present very great rigidity of the carth" as proved by mathematical and physical investigations, but complains of a "want of elasticity" in the methods of the mathematicians (p. 538). According to him, "The hypothesis most compatible with the geological phenomena is that of a central solid nucleus with a molten yielding envelope-not fluid, but viscid or plastic; nor is it necessary that this magma should he of any great thickness; but a thin crust is, it seems to me, an essential condition" (p. 543). Professor Prestwich adduces in support of his views various arguments from geological phenomena which seem of much weight. He has also various arguments of a more or less physical character, but they seem to take a good deal for granted. Thus, on p. 540, referring to plications in the surface rocks, he says, "if the earth were solid throughout, the tangential pressure would resnlt not in distorting or crumpling, but in crushing and breaking. As a rule no such results are to be seen, and the strata have ... yielded, as only a free surface-plate could, to the deformation cansed by lateral pressure ... a yielding bed, on which the crust could move as a separate body, was necessary." It seems to me that as the phenomena of rupture are as yet very imperfectly ascertained, except perhaps for a few simple standard conditions, Professor Prestwich has very little to go on but d̀ priori ideas. I fail to see, for instance, why pressures at or near the surface of a solid sphere should necessarily produce fracture and not How. Also it seems improbable that there would be a sharp line of demarcation so as to enable a crust-which seens clearly to mean a solid superficial layer- to move as a separate body on a "yielding bed." Would not this imply a liquid substratum with no appreciable viscosity? And supposing there were a substratum of this kind, is there any sufficient experimental evidence that a solid crust of even a few miles thickness would on the falling away of the liquid underneath go into folds instead of being crushed and broken? Further, can plications, to the extent shown, say by the Alps, be reconciled with the retention of contemporaneous solidity? Supposing the earth to be essentially solid throughout, is there any reason why the strain at some miles below the surface should not locally at intervals exceed the elastic limit, with the result for a time of a state of flow or plasticity throughout a volume of greater or less extent? During such an epoch there would exist locally conditions somewhat resembling those which Professor Prestwich believes existent everywhere. It is true that one argument adduced by Professor Prestwich and others against the existence of separate reservoirs of molten material-viz. the similarity in the character of volcanic products 
all over the earth-applies equally against such an hypothesis. If, however, volcanic products be supposed to come from several miles below the surface, I see no obvious reason why they shonld not present similar characteristics everywhere. No conclusive argument can well be based on the differences observed in the sedimentary strata, because the conditions under which such strata are deposited are obviously of a varied character.

In varions passages of Professor Prestwich's discussion of the state of the earth one is apt to be puzzled by his falling into the practice, by no means uncommon in geological wlitings, of employing physical terms with a view to oratory rather than to exposition. For instance, he speaks of contraction "due to the yielding of the weaker lines in the crust, when the tension caused by the excessive strain (and of which the first order of movement is an index) overcomes the rosistance, and fractures and doubles up the strata ;" and he adds, "Mountain-ranges are in fact the concluding term of" the stress which caused the deformation of the crust, and the movements which at those times took place must have been influenced by the greater energy of the strains then at work" (p. 546). It is difficult to see here what is intended to be cause and what effect. In fact, while a number of terms are employed which in mathematics and physics have a fairly definite meaning, I must confess my inability to form an adequate conception of what is meant by the passage as a whole.

Professor Prestwich refers (pp. 543, 544) to the hypothesis of the late Professor E. Roche (in the reference to which a misprint gives the year 1861 for 1881) as supplying something of the kind of earth he wants. Thus an examination of Professor Roche's work* may be of some service.

$\mathrm{He}$ supposes the earth to consist of a central nucleus or "bloc," homogeneous but for a possible accumulation of matter of greater density at the centre, and of a superficial liyer of lighter inaterial. Of the nucleus, with the possible exception of a small core of heavier matter, he says, "Sa densité calculée, de 7 à $7 \cdot 5$, indique qu'elle est métallique, sans doute formée de fer..." The specific gravity of the heavier matter which may possibly exist at the centre is, he says, "certainement bien inférieur [to 18], probablement 10 ou 12 (argent, plomb)," p. 235. The outer layer or crust he supposes to have a specific gravity about 3 , and a thickness of about one sixth the earth's radius. Between the crust and the nucleus there exists, it may be everywhere or only locally,

* Acadénie ... de Montpellier, Mémoires de la Section des ściences, tome dixième, $1880-84$, pp. 221-264. 
molten matter such as appears at the surface in volcanic outbursts, but the total volume occupied by this must be small. Professor Roche takes three results as given; viz. the earth's total mass, the eccentricity of its surface, and the ratio of the principal moments of inertia, the last quantity being deduced from astronomical data. He satisfies all the conditions he recognizes by the aid of the following hypothesis regarding his nucleus:- "Ce bloc a pris sa forme définitive sous l'influence d'une rotation moins rapide qu'elle n'est aujourd'hui, et il a conservé l'aplatissement correspondant, malgré les accroissements successifs do vitesse du système résultants de sa contraction progressive" (p. 232). In other words, he assumes the nucleus to have solidified before the crust and that it retains its shape unaltered. Thus as he regards the angular velocity as increasing in consequence of the diminution in the moment of inertia through contraction in cooling, the nuclens possesses a smaller eccentricity than the crust. He supposes only a small difference in the length of the day at the dates of the two solidifications, so thai the difference between the eccentricities of the nucleus and crust is also small. This, Lowever, in no way justifies his hypothesis that the nucleus retains its form unaltered. If its material possessed the properties of an elastic solid the eccentricity would certainly alter, and to an extent probably quite comparable with the alteration that would have occurred if it had remained Huid. Professor Roche seems in fact to treat his nucleus as possessed of the properties of the wholly imaginary perfectly rigid body. He certainly introduces no equations such as ought to hold over the surfice of an elastic solid spheroid. The exact view he adopted as to the properties of solids it is, however, difficult to decide. On his p. 241 a brief statement would imply that he did not regard each elementary layer of a solid sphere as of necessity totally self-supporting; but on $p y .223,224$, where the discussion is fuller, he says, "Si l'on rejette la complète fluidité de la terre, il n'est plus possible d'attribuer à la compressibilité de ses couches la même influence." . . " Dans un solide, les tensions latérales sont variables et acquièrent parfois une valeur énorme. C'est ainsi qu'une couche pourrait se soutenir d'elle-même comme une espèce de voûte, sans peser sur celle qui est au-dessous." A solid layer supporting itself like an arch under the conditions of matter near the earth's surface treated as an elastic solid, presents strains far in excess of those which are regarded here as coming within the range of the mathematical tbeory.

On various grounds it seems to me that the criticism of a want of elasticity, though hardly in the sense intended by 


\section{Applications of Physics and Mathematics to Geology.}

Professor Prestwich, may be strongly urged against Roche's investigations.

Some remarks of M. Roche's, on his pp. 240, 241, throw considerable light on his standpoint and that of many other theorists:- "Les astronomes qui persistent à admettre la fluidité .... cherchent à éluder les objections de Hopkins et de Thomson, en attribuant .... au liquide central une viscosité assez grande pour que .... l'ensemble en arrive à tourner tont d'une pièce .... La masse tournante offre une telle rigidité qu'elle est assimilable sous ce rapport à un bloc solidifié, mais admettre cette assimilation revient à dépouiller le milieu interne des propriétés ordinaires des liquides, et à lui en conserver le nom tont en l'identifiant à un corps solide." He proceeds to point out that the mere question of a name is of no account, considering our ignorance of what would be the properties of matter under such pressures and at such a temperature as the theory of fluidity would lead to. His line of argument is not very clear, but there is no hesitation apparent in his conclusion :-- "En effet, la pression supportée par les couches centrales, dans la supposition d'une complète fluidité, dépasserait deux millions et demi d'atmosphères. La grandeur même de ce nombre est à elle seule une objection péremptoire à l'hypothèse qui y conduit."

Such a position as this may be all very well for a philosopher who supposes the external world a mere idea, the private property of his own mind and so necessarily obedient to laws which his understanding can fully grasp, or for a scientist who believes the earth created for the special purpose of supplying problems of precisely that amount of difficulty which he personally is able to solve, but from a common-sense point of view it seems utterly irrational. No physicist or geologist has any reason to suppose that there are not numerous problems whose full comprehension requires more extensive knowledge than is possessed by himself or any of his contemporaries.

The necessity for theories has been eloquently urged by Professor Darwin *, who says "A theory is, then, a necessity for the advance of science, and we may regard it as the branch of a living tree, of which facts are the nourishment." Employing this simile, I must confess that the subject treated in this paper resembles, in my opinion, a tree which combines a sad deficiency of sap with a great superfluity of branches. It will, I dare say, be generally admitted that the premature craving

* 'Nature,' vol, xxxiv. (1886) p. 420 , Address to British Association, Section A. 
after a finality of knowledge has been responsible for numerous fruitless speculations in the past, and it seems only too probable that the impatience of the mind with its own ignorance is the principal foundation of much of the theory of to-day. The satisfaction derived from the contemplation of simple and comprehensive laws may suffice perhaps to prove that the powers of the mind are limited, but hardly that the processes of nature are simple.

XLIV. On the Specific Heat of Basalt. By W. C. RoвerTsAusten, C.B., F.R.S., and A. W. RüCKER, F.R.S.*

$\mathrm{H}$ AVING been asked by the Rev. O. Fisher to determine for him the latent heat of basalt, we made some experiments on a specimen which was furnished to us by Prof. Jadd.

Fragments of the rock were melted in a platinum crucible, and the junction of a thermal couple consisting of platinum with platinum containing 10 per cent. of rhodium was immersed in the pasty mass, which was then allowed to cool. The scale of the galvanometer had previously been standardized by an observation on the solidifying-point of pure gold, and the pyrometer was standardized from time to time by the same means. When the index spot of light reached the desired point the wires were nipped off close to the basalt, and the crucible and its contents were plunged into 1000 grams of water contained in a silver calorimeter. The water was stirred by a screw or fan of silver which was rotated by an electric motor. The temperature was read by means of a mercurial thermometer which had been carefully corrected.

The two main sources of error in the experiments are probably an uncertainty as to the mean temperature of the basaltic mass owing to its being a bad conductor of heat, and the fact that in the processes of heating and cooling it undergoes more or less important changes of constitution.

The first error was reduced to sinall proportions by using small quantities of basalt, the mass employed rarely much exceeding 20 grams.

The second error is in part unavoidable. The rapidly cooled basalt was always glassy like olivine. We also found that frequent heatings and coolings, and the nature of the flame-whether oxidizing or reducing-employed to heat the mass appeared to affect the results very seriously.

In some experiments the crucible was heated in the flame

* Communicated by the Authors.

Plit. Mag. S. 5. Vol. 32. No. 197. Oct. 1891. 2 B 